\title{
Contribution of Substance P and Neurokinin A to the Differential Injury-Induced Thermal and Mechanical Responsiveness of Lamina I and V Neurons
}

\author{
Javier Mazarío $^{1}$ and Allan I. Basbaum ${ }^{2}$ \\ ${ }^{1}$ Laboratorio de Función Sensitivomotora, Hospital Nacional de Parapléjicos, 45071 Toledo, Spain, and ${ }^{2}$ Departments of Anatomy and Physiology and \\ W. M. Keck Center for Integrative Neuroscience, University of California San Francisco, San Francisco, California 94158
}

\begin{abstract}
In a previous report, we compared the properties of lamina $\mathrm{V}$ neurons of the spinal cord dorsal horn in wild-type mice and in mice with a deletion of the preprotachykinin-A (PPT-A) gene, which encodes substance P (SP) and neurokinin A (NKA). The mutant mice had pronounced deficits in the response to thermal stimulation, both before and after mustard oil induced sensitization. Here, we extended our analysis to the properties of lamina I neurons and also examined responsiveness to mechanical stimulation. Consistent with the properties of lamina V neurons, in the PPT-A mutant mice we found significantly reduced responses of lamina I neurons to noxious thermal stimulation, and mustard oil sensitization of these neurons to heat was lost. In contrast, not only were the responses of lamina I neurons to noxious mechanical stimulation unchanged in the mutant mice, but in neither the wild-type nor the mutant mice could sensitization be induced. However, mustard oil profoundly sensitized lamina V neurons to mechanical stimulation in both wild-type and mutant mice. We conclude that SP and/or NKA are required for the transmission of noxious thermal stimulation by lamina I and $\mathrm{V}$ neurons, both before and after tissue injury. The persistence of mechanical sensitization of lamina $\mathrm{V}$ neurons in the mutant mice further shows that mustard oil induces mechanical and thermal sensitization through different mechanisms. Finally, we conclude that lamina I sensitization to mechanical stimulation is not required for this form of injury-increased responsiveness of lamina $\mathrm{V}$ neurons.
\end{abstract}

Key words: pain; tachykinins; mustard oil; knock-out; dorsal horn; allodynia

\section{Introduction}

The primary afferent nociceptor contains a mix of neurotransmitters that either directly activate "pain" transmission neurons of the dorsal horn or regulate the output of these postsynaptic neurons. Of particular interest are the tachykinins, substance $\mathrm{P}$ (SP) and neurokinin A (NKA), which are products of the preprotachykinin A (PPT-A) gene. These peptides are synthesized by nociresponsive small diameter primary afferents, project to areas of the spinal cord involved in the processing of nociceptive information, including lamina I, II, V, and X (Bessou and Perl, 1969; Hökfelt et al., 1975a,b; Cuello and Kanazawa, 1978; LaMotte, 1988), and are released into the CSF by noxious stimulation (Yaksh et al., 1980). SP and NKA bind to the neurokinin 1 (NK-1) receptor, which is heavily expressed by projection neurons of the superficial dorsal horn (Alexander et al., 2001; Todd et al., 2002).

Tachykinins are important contributors to nociceptive processing. Thus, iontophoresis of SP excites nociresponsive dorsal horn neurons and intrathecal injection of SP induces pain behaviors (Yasphal et al., 1982; Moochhala and Sawynok, 1984). Furthermore, selective NK-1 receptor antagonists are antinocicep-

Received July 14, 2006; revised Dec. 13, 2006; accepted Dec. 13, 2006.

This work was supported by National Institutes of Health Grants NS14627 and NS48499.

Correspondence should be addressed to Javier Mazarío, Laboratorio de Función Sensitivomotora, Hospital Nacional de Parapléjicos, 45071 Toledo, Spain. E-mail: jmazario@sescam.jccm.es.

DOI:10.1523/JNEUROSCI.2992-06.2007

Copyright $\odot 2007$ Society for Neuroscience $\quad$ 0270-6474/07/270762-09\$15.00/0 tive in animals (Hill, 2000). There is, however, less agreement among studies of mice with a deletion of the PPT-A gene (Cao et al., 1998; Zimmer et al., 1998) or of the NK-1 receptor (De Felipe et al., 1998; Weng et al., 2001). Some studies reported a significant loss of injury-induced enhancement of nociceptive processing (central sensitization), but others only found deficits in acute pain processing (Cao et al., 1998; De Felipe et al., 1998; Mansikka et al., 1999; Mansikka et al., 2000; Martinez-Caro and Laird, 2000; Laird et al., 2001; Weng et al., 2001).

We previously reported that lamina $\mathrm{V}$ nociresponsive neurons in PPT-A mutant mice encode for different intensities of thermal stimulation and sensitize after tissue injury. However, the duration of the evoked response in PPT-A mutant mice was significantly reduced compared with wild-type (wt) animals, both before and after sensitization (Martin et al., 2004). The relative normality of the responses of lamina $\mathrm{V}$ neurons in the PPT-A mutant mouse argues that these neurons are not critical contributors to the behavioral phenotype in these mice. For this reason, in the present study we turned our attention to the responsiveness of neurons in lamina I, the majority of which express the NK-1 receptor and are responsive to SP. In the course of this study, we also extended our analysis of the responses of lamina $\mathrm{V}$ neurons to innocuous and noxious mechanical stimulation. We report that SP-NKA are important contributors to the transmission of noxious thermal but not mechanical information by both lamina I and V neurons. We also demonstrate a significant dif- 
ferential contribution of lamina I and $\mathrm{V}$ neurons to the processing of mechanical and thermal information after mustard oilinduced tissue injury.

\section{Materials and Methods}

All experiments were reviewed and approved by the Institutional Animal Care and Use Committee at the University of California San Francisco. The PPT-A-knock-out mice were generated as described previously (Cao et al., 1998). Heterozygous littermates were used for breeding. The experiments were performed in $27 \mathrm{wt}$ and 41 PPT-A knock-out (ko) mice of either sex weighing 20-45 g. The experimenter was blind to the genotype.

Surgical procedures. Animals were anesthetized with $1.3 \mathrm{~g} / \mathrm{kg}$ urethane ( $10 \%$ in saline, i.p.; Sigma, St. Louis, MO) and then injected subcutaneously with dexamethasone $(0.2 \mathrm{mg}$; American Regent Laboratories, Shirley, NY) and atropine ( $0.3 \mathrm{mg}$; Sigma) to minimize spinal cord swelling and to reduce secretions, respectively. Bupivicaine $(\sim 100 \mu \mathrm{l})$ was injected subcutaneously at the surgical site. We attached electrocardiogram electrodes to the animal and monitored heart and breathing rate continuously during surgery. These were maintained at 9-11 and 2-4 $\mathrm{Hz}$, respectively. We administered supplemental doses of anesthetic as needed. A laminectomy was then performed at vertebrae T13 to L1 to expose spinal levels L4-L5. Only when all bleeding was contained was the dura incised and the mouse placed in a specialized head holder, with the vertebral segments on both sides of the laminectomy clamped firmly. A spinal pool was then formed with 5\% agar (Sigma) and filled with mineral oil. Core temperature was monitored continuously and maintained at $37 \pm 0.5^{\circ} \mathrm{C}$ with a circulating hot water pad and a feedback controlled infrared lamp. Mice breathed spontaneously throughout the experiment.

Data acquisition. Fine tip $(<1 \mu \mathrm{m})$ tungsten microelectrodes $(10 \mathrm{M} \Omega$; Frederick Haer, Brunswick, ME) were inserted into the spinal cord to record extracellular potentials at a depth of $20-200 \mu \mathrm{m}$ for lamina I neurons and 400-650 $\mu \mathrm{m}$ for lamina $\mathrm{V}$ neurons (recorded in different animals). The potentials were amplified, filtered, and recorded using standard electrophysiological techniques. The activity of single units was acquired, digitized, and discriminated by computer using a $\mu 1401$ processor and Spike 2 software (CED, Cambridge, UK). In four cases (two wt and two mutant), two neurons were recorded simultaneously, but these were analyzed independently. Brushing and/or light pressure applied to the glabrous skin of the ipsilateral hindpaw were used as search stimuli. We used two different stimulation protocols (thermal and mechanical) in these studies. Because of the nature of the stimulation devices, animals were tested either for mechanical or thermal responsiveness, but not both. Neurons were classified as wide dynamic range (WDR) or nocispecific (NS) according to their responsiveness to mechanical stimulation. Those responding to the lowest (brush; $130 \mathrm{mN}$ ) and highest (pinch; 430 $\mathrm{mN}$ ) intensity of mechanical stimulation were considered WDR. Those not responding to low-intensity stimulation but still responding to highintensity stimulation were classified as NS.

Thermal stimulation. We recorded spontaneous activity of lamina I neurons for $2 \mathrm{~min}$ before testing their responsiveness to $10 \mathrm{~s}$ of brush, $10 \mathrm{~s}$ of pressure, and a 1-2 s pinch (Fig. 1). To characterize the thermal responsiveness of these neurons, we positioned a $3 \times 3 \mathrm{~mm}$ copper probe, heated and cooled by a $9 \mathrm{~W}$ Peltier effect device $\left(2^{\circ} \mathrm{C} / \mathrm{s}\right.$ rate of rise $)$, onto the receptive field. A thermal conducting paste (Thermolink 1000; Aavid Thermal Technologie, Laconia, $\mathrm{NH}$ ) was applied to the probe to improve stimulus delivery. Each of the thermal stimuli $\left(40,45\right.$, and $\left.49^{\circ} \mathrm{C}\right)$ was applied for $10 \mathrm{~s}$ and at least $60 \mathrm{~s}$ separated each stimulus application. The thermode was maintained at $36 \pm 0.5^{\circ} \mathrm{C}$ between stimulation periods. Only neurons that encoded these thermal stimuli were considered for analysis.

Only after characterizing the thermal responsiveness of the neurons did we test the effects of mustard oil (MO) (3-isothiocynato-prop-1-ene; Sigma). The MO was diluted to $10 \%$ in mineral oil and applied around the probe tip with a paintbrush $(\sim 60 \mu \mathrm{l})$, and then we recorded the neuronal responses for the next $10 \mathrm{~min}$. At the end of this period, we again tested the responsiveness of the neurons to graded thermal stimuli, at 10,40 , and $60 \mathrm{~min}$ after the MO administration.

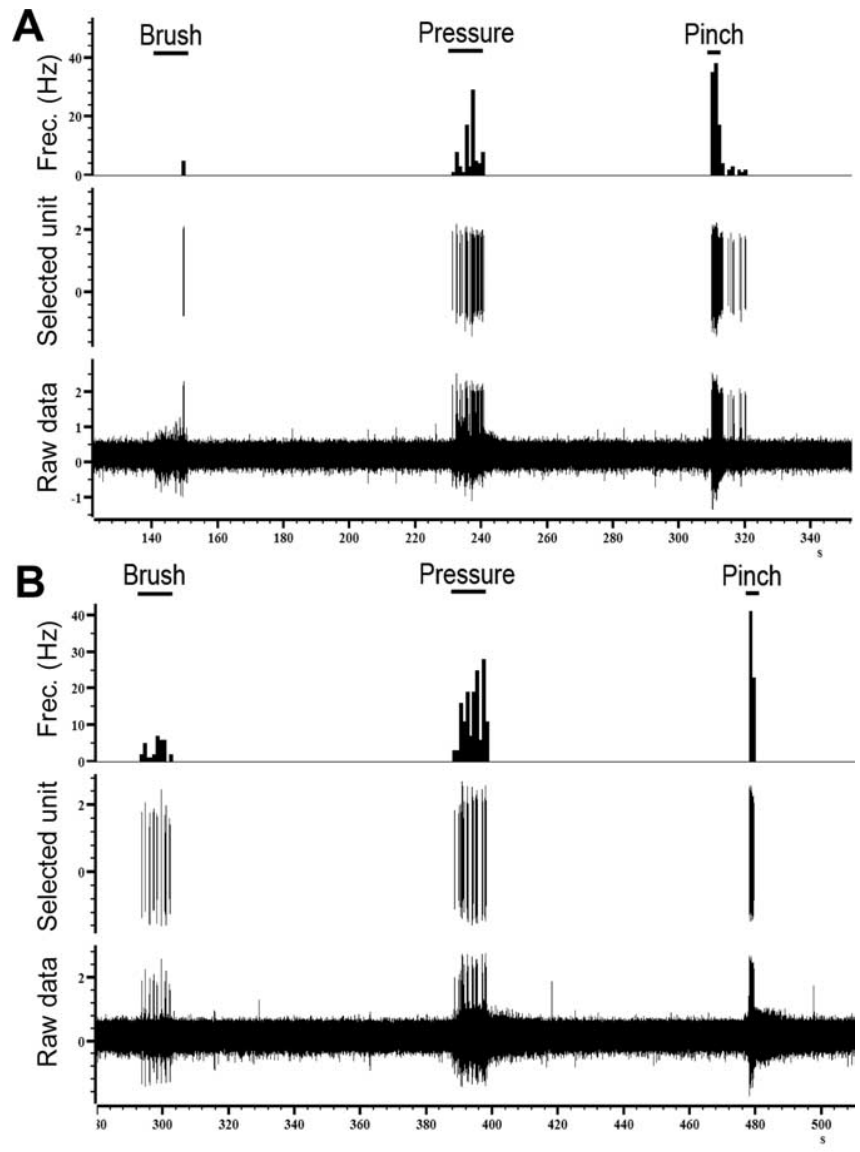

C

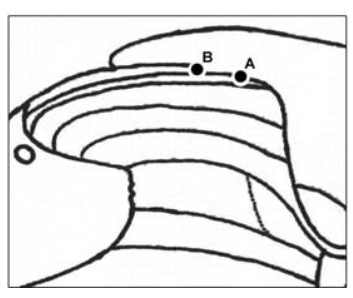

Figure 1. Original recordings from lamina I neurons of a wt $(\boldsymbol{A})$ and a mutant mouse $(\boldsymbol{B})$ and their responses to brush, pressure, and pinch. $($ shows the recording sites of each neuron.

Mechanical stimulation. We first established that the neuron responded to noxious heat. After recording spontaneous activity for $2 \mathrm{~min}$, we immersed the hindpaw in $50^{\circ} \mathrm{C}$ water for $1-3$ s to confirm a thermal response. Next, we placed a computer-controlled mechanical stimulator (ESTIMEC, Cibertec, Spain) with a surface of $12 \mathrm{~mm}^{2}$ over the receptive field of the neuron, and then applied 10 s stimuli of 130, 230, 330, and 430 $\mathrm{mN}$ to the paw. At least $90 \mathrm{~s}$ separated consecutive stimuli. Only neurons that responded to the $50^{\circ} \mathrm{C}$ stimulus and encoded mechanical stimulation were subsequently analyzed. Because we found that some lamina $\mathrm{V}$ neurons showed adaptation to repeated mechanical stimulation, we only analyzed neurons with similar responses to three sets of mechanical stimuli applied at $5 \mathrm{~min}$ intervals. Finally, we tested the effects of MO applied around the tip of the probe using a protocol similar to that described above for thermal stimulation.

Data analysis. We quantified the results using Spike 2 software (CED). The total number of spikes recorded after each stimulus was counted and used for statistical analysis. Peak firing for each stimulus (in $1 \mathrm{~s}$ bins) was also studied. The data were analyzed using one-way or repeatedmeasures ANOVA (within genotype) or two-way ANOVA (among genotypes) followed by post hoc comparisons. Student's $t$ tests were used for comparisons when only two means were generated. All statistical analyses were performed using GraphPad Prism (GraphPad Software, San Diego, CA). Data are presented as mean \pm SEM. 


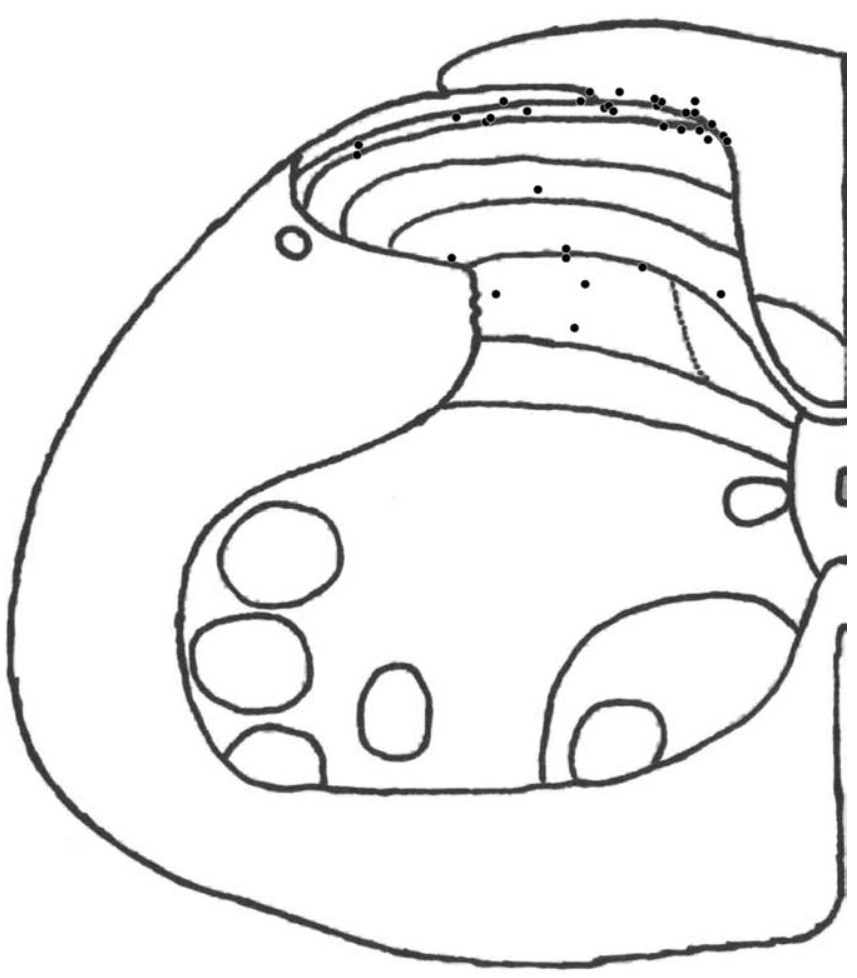

Figure 2. Diagram showing the position of 36 neurons recorded in these experiments.

Histology. At the end of the experiment, we made a small lesion in the spinal cord, by passing current through the electrode ( $10 \mu \mathrm{A}$ for $5 \mathrm{~s})$. The animal was then perfused transcardially with $10 \mathrm{ml}$ of $0.9 \%$ PBS followed by $30 \mathrm{ml}$ of $10 \%$ formalin in phosphate buffer (PB). The L3-L6 segments of the spinal cord were removed and kept in $10 \%$ formalin in PB. The tissue was cryoprotected in a PB-30\% sucrose solution and $40 \mu \mathrm{m} \mathrm{sec}-$ tions were cut with a freezing microtome, mounted on slides, stained with cresyl violet, and coverslipped. The center of the lesion site was used to indicate the recording sites of 36 of the neurons studied (Fig. 2).

\section{Results}

\section{Lamina I thermal stimulation}

In this analysis, we recorded the activity of a total of 10 neurons from wt (6 WDR and 4 NS) and 17 neurons from mutant mice (8 WDR and 9 NS). The depths of the recording sites for wt and mutant mice $(85.2 \pm 21.2$ and $91.2 \pm 12.8 \mu \mathrm{m}$, respectively), which corresponded to the point at which neuronal firing was first detected, did not differ. Neurons from both genotypes also had comparable spontaneous activity $(0.6 \pm 0.4 \mathrm{~Hz}$ for wt and $0.5 \pm 0.2 \mathrm{~Hz}$ for mutant animals).

\section{Nocispecific neurons}

Thermal stimulation of the receptive field of the neurons induced a temperature-dependent increase of the firing rate in both genotypes. However, we found that NS neurons from mutant mice showed a significantly reduced responsiveness compared with wt NS neurons $\left(F_{(1,18)}=8.256 ; p=0.0074\right)$ (Figs. 3, $\left.4 A\right)$. Post hoc analyses established that the responses to $45^{\circ}(54.1 \pm 23.4 \mathrm{~Hz}$ for wt and $6.53 \pm 2.2 \mathrm{~Hz}$ for ko $)$ and $49^{\circ} \mathrm{C}(55.55 \pm 6.84 \mathrm{~Hz}$ for wt and $9.44 \pm 3.17 \mathrm{~Hz}$ for ko) were significantly reduced in the mutant mice $(p<0.01)$ (Fig. $4 A)$. However, peak firing was similar for both genotypes. In contrast to what we previously observed for lamina $\mathrm{V}$ neurons, we did not observe differences in afterdischarge at any of the three temperatures tested.

Topical application of MO produced a dramatic increase of the firing rate, but there were no significant differences between

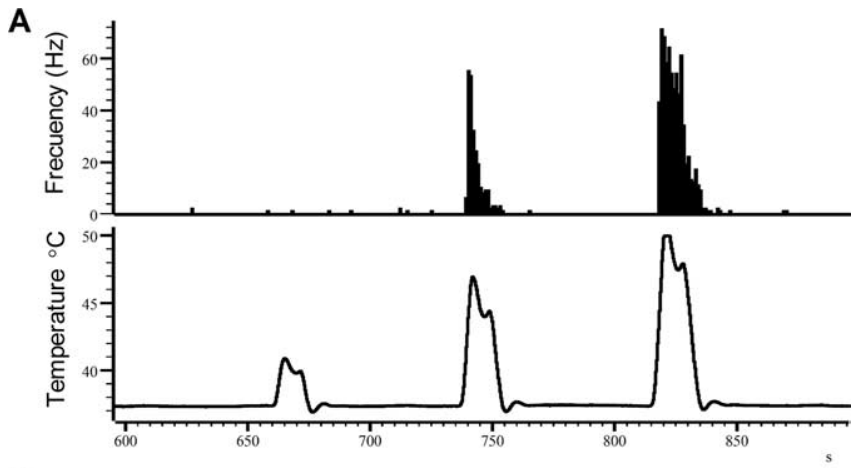

B

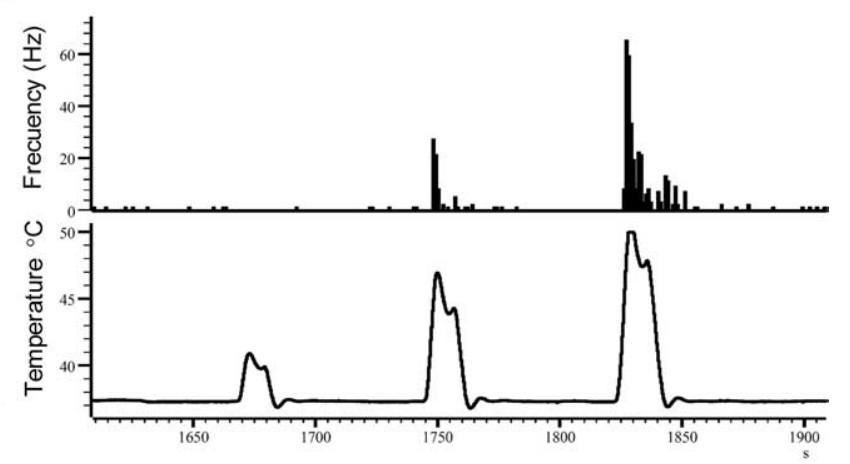

C

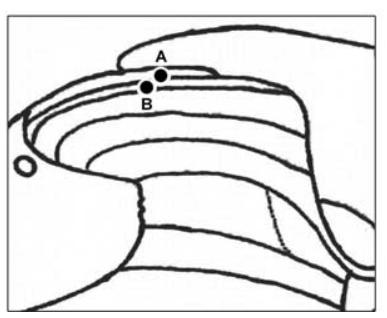

Figure 3. Examples of the responses of lamina I neurons to graded thermal stimuli in a wt $(\boldsymbol{A})$ and a mutant mouse $(\boldsymbol{B})$ and their recording sites $(\boldsymbol{C})$.

wt and mutant mice in peak firing $(75 \pm 18 \mathrm{~Hz}$ vs $43.3 \pm 7.6 \mathrm{~Hz}$, respectively) or in total number of spikes during the first $10 \mathrm{~min}$ after MO (14,282 $\pm 12,549$ spikes vs $6435 \pm 2256$ spikes, respectively). After $\mathrm{MO}$, the firing rate (recorded for $30 \mathrm{~s}$ before each series of thermal stimuli) varied significantly over time $\left(F_{(2,27)}=\right.$ $5.57 ; p<0.01)$, but this was only significant for wt mice, and only at the first time point measured after $\mathrm{MO}(10 \mathrm{~min} ; p<0.01)$. This indicates that the duration of the response to $\mathrm{MO}$ is somewhat reduced in mutant compared with wt mice.

$\mathrm{MO}$ also profoundly sensitized the response of these neurons to thermal stimulation. There was a significant increase in the response to the $40^{\circ} \mathrm{C}$ stimulus $\left(F_{(2,30)}=6.643 ; p=0.0041\right)$. Post hoc tests showed that this difference was significant, but again only for wt mice at the 10 min post-MO time point (Fig. $5 A)(p<$ $0.05)$. However, after $\mathrm{MO}$, there was no increase of the response to 45 or $49^{\circ} \mathrm{C}$ (Fig. $5 \mathrm{~B}, \mathrm{C}$ ), compared with their respective controls.

\section{Wide dynamic range neurons}

As for NS neurons, heating the receptive field of the WDR neurons induced a temperature-dependent increase of the firing rate, but for WDR neurons we did not observe differences between genotypes in total (Fig. $4 B$ ) or peak firing. Also, in contrast to NS neurons, after MO the firing rate of WDR neurons (recorded for 

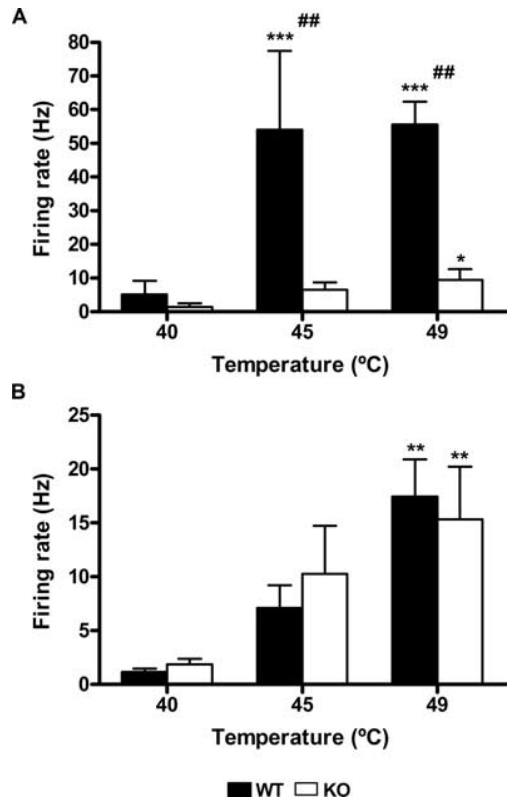

Figure 4. Lamina l: temperature coding. Both NS $(\boldsymbol{A})$ and WDR $(\boldsymbol{B})$ neurons encoded noxious thermal stimuli in wt (filled bars) and mutant animals (open bars), but the responses of the NS neurons in the mutant mice are significantly reduced compared with the wt $\left({ }^{*} p<0.05,{ }^{* *} p<\right.$ $0.01,{ }^{* * *} p<0.001$ vs control; ${ }^{\# \#} p<0.01$ between genotypes). Error bars indicate SEM.

$30 \mathrm{~s}$ before each series of thermal stimuli) did not vary significantly over time.

$\mathrm{MO}$ application to the paw induced an increase of the firing rate of the neurons that was similar for wt and mutant mice. This was the case whether we compared total activity evoked during the 10 min after drug administration (4449 \pm 1118 spikes vs $4247 \pm 2014$ spikes, respectively) or peak firing ( $41.3 \pm 13.4$ for the wt and $49.8 \pm 18$ for the mutant). There was also a significant increase of the responses of the WDR neurons to $40^{\circ} \mathrm{C}$ stimulation after $\operatorname{MO}\left(F_{(2,28)}=3.459 ; p=0.0454\right)$. Post hoc analysis showed that this change was only significant for wt mice at the 10 min post-MO time point (Fig. $5 A)(p<0.05)$. Similarly to what we observed for NS neurons, after $\mathrm{MO}$, there was no change of the response to 45 or $49^{\circ} \mathrm{C}$ (Fig. $5 \mathrm{~B}, \mathrm{C}$ ), for any of the genotypes.

Together, these data indicate that there is a deficit in the responsiveness of lamina I NS neurons to noxious thermal stimulation in the PPT-A null mice and that the lack of SP and NKA in these mice prevents both WDR and NS lamina I neurons from sensitizing to thermal stimulation after MO.

\section{Lamina I: mechanical stimulation}

We recorded responses to mechanical stimulation from a total of 19 cells in wt (10 WDR and 9 NS) and 18 (10 WDR and 8 NS) cells in mutant mice. As in the previous sample, there were no significant differences in spontaneous activity of the neurons between wt and mutant mice $(0.14 \pm 0.05$ and $0.22 \pm 0.12$, respectively). Neurons in the wt group were recorded at a depth of $105.7 \pm$ $14.61 \mu \mathrm{m}$. In the mutant, the mean depth of recording was $131.6 \pm 14.85 \mu \mathrm{m}$. No significant differences were observed in the mean depth of the recording site in any of the groups in which lamina I cells were studied.

\section{Nocispecific neurons}

Mechanical stimulation of the receptive fields of the neurons induced a force-dependent increase of their activity (Figs. 6A, 7). The magnitude of the increase was comparable in wt and mutant
A

40 DEGREES
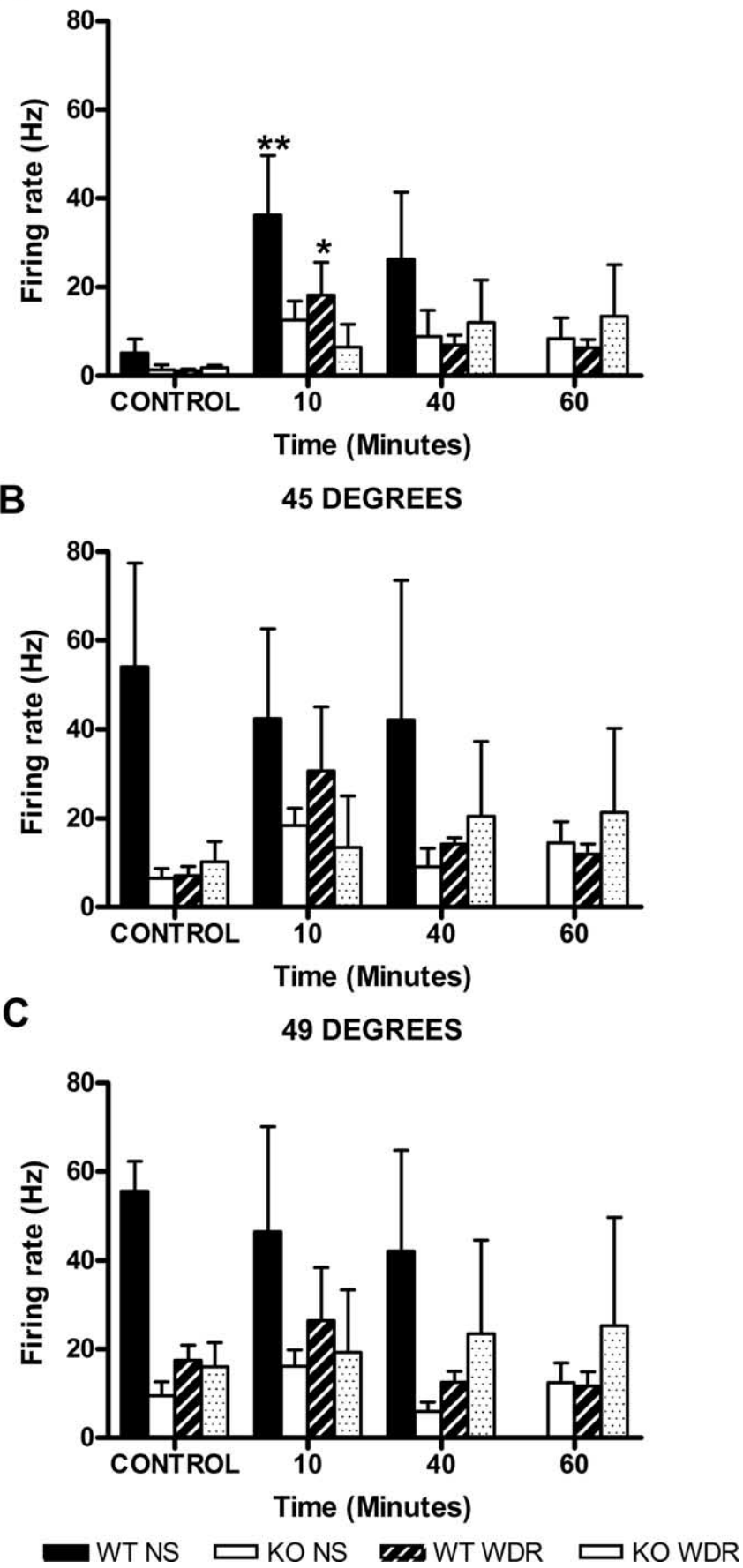

Figure 5. Lamina I:M0 sensitizes neurons to thermal stimuli. Time course of the responses of lamina I neurons before (CONTROL) and after the administration of mustard oil to $40^{\circ} \mathrm{C}(\boldsymbol{A}), 45^{\circ} \mathrm{C}$ $(\boldsymbol{B})$, and $49^{\circ} \mathrm{C}(\boldsymbol{C})$ in wt and mutant mice $\left({ }^{*} p<0.05 ;{ }^{* *} p<0.01\right.$ vs control). Error bars indicate SEM.

animals. As for the neurons tested in the thermal protocol, MO application to the paw significantly increased the firing rate of the neurons. The total activity recorded for the $10 \mathrm{~min}$ after $\mathrm{MO}$ was $3133 \pm 1181$ spikes for the wt and $8651 \pm 4115$ spikes for the mutant, with a peak firing rate of $56.7 \pm 31.7$ and $77.25 \pm 27.35$ $\mathrm{Hz}$, respectively. These data did not differ significantly between genotypes. Ten minutes after $\mathrm{MO}$, there was a significant increase on the firing rate of NS neurons in the wt $(p<0.05)$ but not in the mutant mice. But, in distinct contrast to the profound ther- 


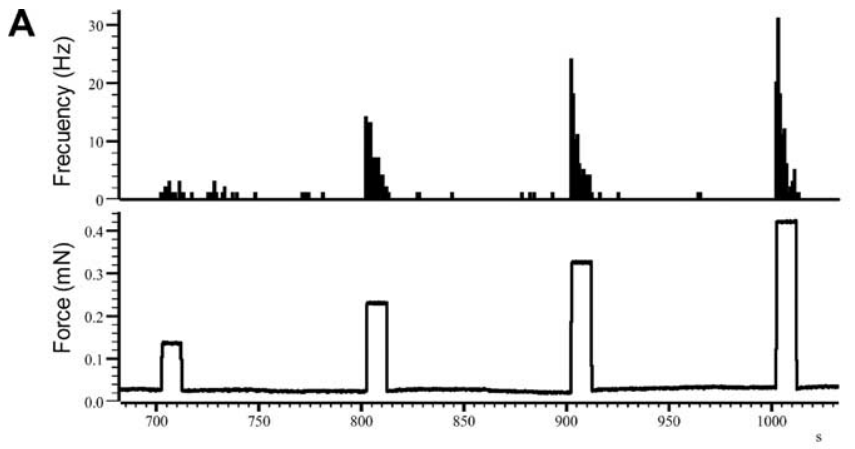

B

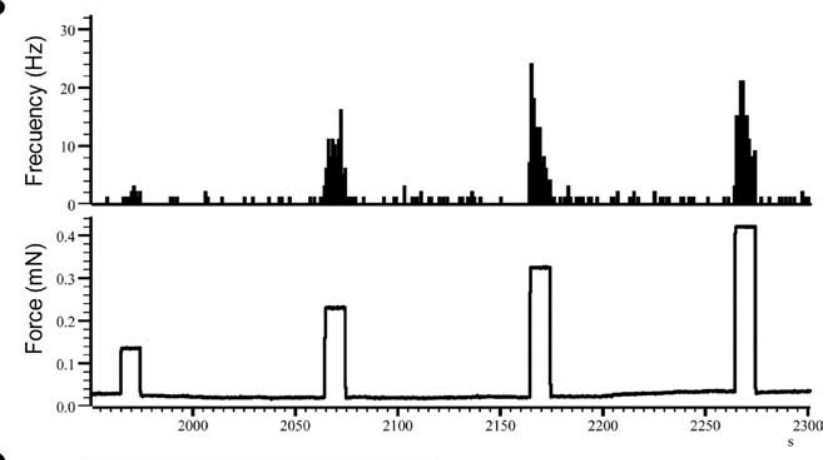

C

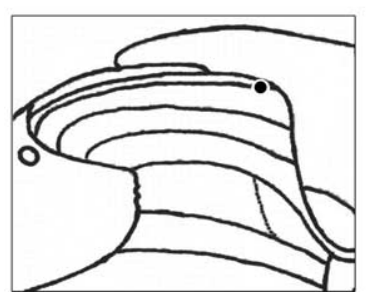

Figure 6. Example of the responses of a lamina I neuron to graded mechanical stimuli before $(\boldsymbol{A})$ and 10 min after $(\boldsymbol{B})$ the application of mustard oil to the receptive field of the neuron. The recording site of the neuron is shown in $\boldsymbol{C}$.

mal sensitization of lamina I neurons produced by $\mathrm{MO}$, we found no change in the frequency of firing of lamina I neurons at any of the forces applied, at any time point and for either genotype (Figs. $6,8)$. Furthermore, there were no differences in peak firing or afterdischarge between genotypes.

Wide dynamic range neurons

Similar to what was observed for NS neurons, WDR responded to $\mathrm{MO}$ by increasing their firing rate (Fig. 7). In the $10 \mathrm{~min}$ after $\mathrm{MO}$ application, neurons from wt and mutant mice discharged a total of $2880 \pm 688$ and $3484 \pm 1949$ spikes, respectively (no significant difference). After the initial barrage of activity evoked by $\mathrm{MO}$, no differences were observed between basal activity and the activity recorded for the $30 \mathrm{~s}$ that preceded each stimulation series. This was true for both genotypes. Finally, as for NS neurons, we found that MO did not sensitize WDR neurons to mechanical stimulation, at any of the time points studied (Fig. 8).

These results show that SP and NKA are not necessary for the processing of mechanical stimulation by lamina I NS or WDR neurons, before or after MO-induced injury. Also, these results demonstrate that there are major differences in the sensitizability of lamina I neurons to thermal and mechanical stimulation.

\section{Lamina V: mechanical stimulation}

To determine whether the same was true for neurons in the region of lamina $\mathrm{V}$, we repeated the mechanical analysis for neu-
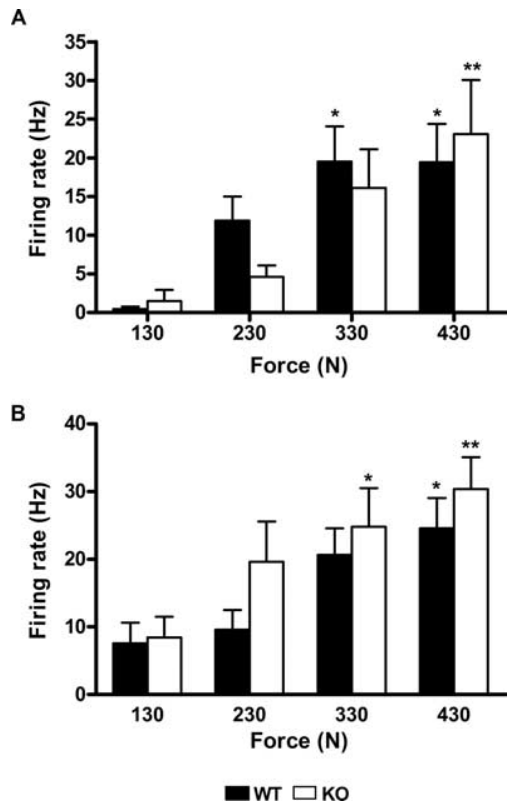

Figure 7. Lamina l: force (mechanical) coding. The NS $(\boldsymbol{A})$ and WDR $(\boldsymbol{B})$ neurons of both wt (filled bars) and mutant animals (open bars) encode for graded mechanical stimuli with no differences between genotypes $\left({ }^{*} p<0.05 ;{ }^{* *} p<0.01\right.$ vs control). Error bars indicate SEM.

rons recorded at a mean depth of $519.78 \pm 32.58 \mu \mathrm{m}$ in wt animals (seven WDR and three NS) and at $514.88 \pm 33.50 \mu \mathrm{m}$ in mutant animals (five WDR and three NS).

The responses recorded in both genotypes from lamina $\mathrm{V}$ neurons were similar for WDR and NS neurons, both before and after $\mathrm{MO}$ application. The only difference that we observed was in the responses of these neurons to $130 \mathrm{mN}$, before MO. In this condition, NS neurons in the wt discharged at a rate of $0.13 \pm$ $0.09 \mathrm{~Hz}$, whereas WDR neurons discharged at $9.94 \pm 2.72 \mathrm{~Hz}$. For mutant mice, the responses evoked by $130 \mathrm{mN}$ were at $0.65 \pm$ 0.3 and $13.1 \pm 4.14 \mathrm{~Hz}$ for NS and WDR neurons, respectively. Because we found no significant different between genotypes, the data from WDR and NS neurons of each genotype were pooled.

As for the lamina I neurons, we found no significant difference in the spontaneous activity of lamina $\mathrm{V}$ neurons between wt $(0.18 \pm 0.04 \mathrm{~Hz})$ and mutant $(0.38 \pm 0.16 \mathrm{~Hz})$ mice. In response to mechanical stimulation, the neurons from both wt and mutant animals increased their firing rate, in a force-dependent manner, to a similar degree (Fig. 9). Furthermore, MO application to the paw increased the firing rate of these neurons in both wt and mutant animals. For the $10 \mathrm{~min}$ after MO, we recorded 13,090 \pm 5515 spikes and 13,420 \pm 5744 spikes in wt and mutant mice, respectively. These values were not significantly different. However, peak firing was significantly higher for wt $(87.20 \pm 12.19$ $\mathrm{Hz})$ compared with mutant mice $(51.00 \pm 10.16 \mathrm{~Hz} ; p<0.05)$.

In contrast to the lack of mechanical sensitization of lamina I neurons, we found that MO produced a profound sensitization of lamina $\mathrm{V}$ neurons to mechanical stimulation (Fig. 10). Importantly, this was true in both wt and mutant animals. This is particularly notable for the responses evoked by the $130 \mathrm{mN}$ stimulus $\left(F_{(3,46)}=8.23 ; p=0.0002\right)$ (Fig. $11 \mathrm{~A}$ ), which was the lowest intensity studied, and which before $\mathrm{MO}$ evoked a minimal response. Post hoc tests showed that the increase in post MO was significant for the wt 10 and 40 min after $\mathrm{MO}(p<0.001$ and $p<$ 0.05 , respectively) and for the mutant 10 min after $\mathrm{MO}(p<$ 0.05). The responses elicited $10 \mathrm{~min}$ after $\mathrm{MO}$ at this intensity of stimulation did not differ from those obtained before MO at 330 
A

$130 \mathrm{mN}$

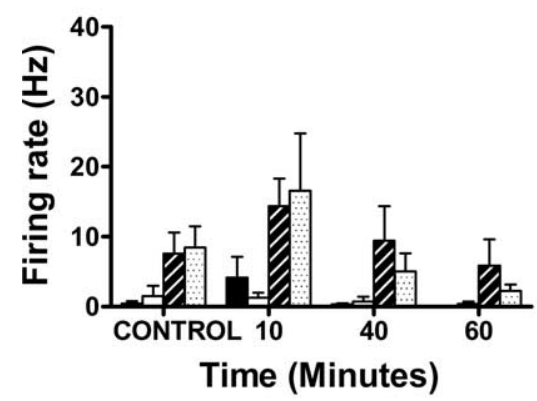

C

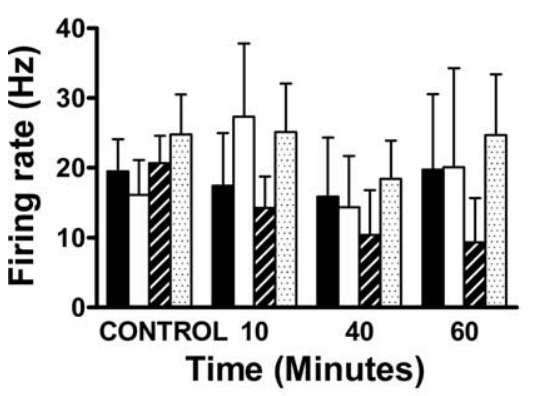

B

$230 \mathrm{mN}$

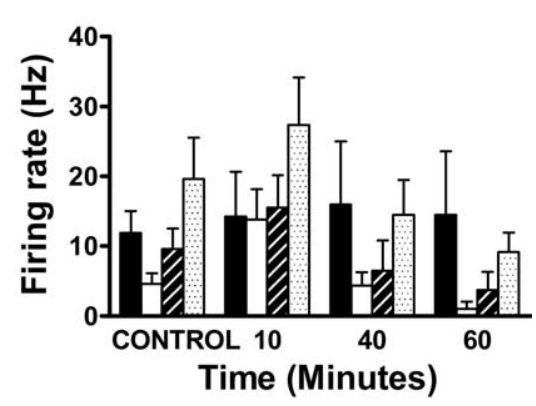

D

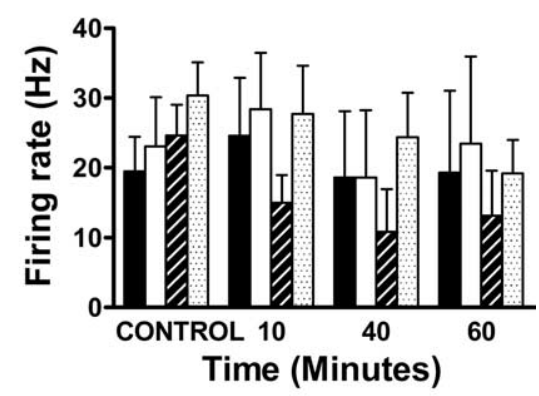

WT NS $\square$ KO NS

VISWT WDR

KO WDR

Figure 8. Lamina I: mustard oil does not sensitize lamina I neurons to mechanical stimuli. Responses of lamina I neurons to 130 $\mathrm{mN}(\boldsymbol{A}), 230 \mathrm{mN}(\boldsymbol{B}), 330 \mathrm{mN}(\boldsymbol{C})$, and $430 \mathrm{mN}(\boldsymbol{D})$ mechanical stimuli before (CONTROL) and after the application of mustard oil, in wt and mutant mice. Error bars indicate SEM.

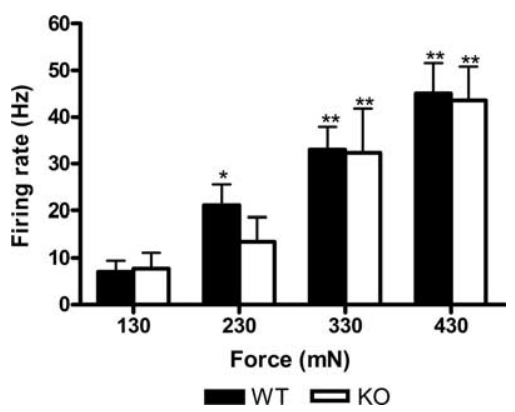

Figure 9. Lamina V: force (mechanical) coding. Neurons in both wt (filled bars) and mutant animals (open bars) encode mechanical stimulus intensity. wt and mutant mice did not differ $\left({ }^{*} p<0.05,{ }^{* *} p<0.01\right.$ vs control). Error bars indicate SEM.

$\mathrm{mN}(42.84 \pm 10.85$ vs $33.01 \pm 4.85 \mathrm{~Hz}$, respectively, for the wt, and $35.93 \pm 8.23$ vs $42.43 \pm 10.66 \mathrm{~Hz}$, respectively, for the ko) (Fig. $11 A, C$ ), and there were no significant differences between genotypes. For the $230 \mathrm{mN}$ stimulus (Fig. $11 \mathrm{~B}$ ), $10 \mathrm{~min}$ after $\mathrm{MO}$ there was an increase of the responses in both the wt (from $21.14 \pm 4.42$ to $42.91 \pm 9.40 \mathrm{~Hz}$ ) and the mutant (from $24.74 \pm$ 10.03 to $50.41 \pm 9.17 \mathrm{~Hz}$ ), but these increases were not significant. These data suggest that there is a sensitization across stimulus intensities, but there may be a ceiling effect at the higher intensities, making it difficult to observe statistically significant changes. Consistent with this hypothesis, MO application did not induce any changes of the responses to 330 or $430 \mathrm{mN}$ either in wt or in mutant animals (Fig. 11C,D). Finally, peak firing and afterdischarge did not differ between genotypes when compared at the same time point and for the same stimulus.

\section{Discussion}

These results demonstrate that SP and NKA are necessary contributors to the normal processing of thermal information by lamina I nocispecific neurons of the lumbar spinal cord. The tachykinins also contribute to the sensitization to thermal stimulation by an intense inflammatory stimulus. Somewhat surprisingly, however, we found that these peptides are less relevant to the processing of mechanical information. This was true for both lamina $\mathrm{I}$ and $\mathrm{V}$ neurons. MO also failed to sensitize lamina I neurons to mechanical stimulation, although it did sensitize lamina $\mathrm{V}$ neurons in both genotypes. We conclude that the mechanisms by which MO induces thermal and mechanical sensitization are not only different but that sensitization of lamina I neurons to mechanical stimulation is not necessary for its manifestation in neurons of lamina $\mathrm{V}$.

\section{Thermal deficits in the mutant mice}

Because lamina I WDR neurons responded normally to thermal stimulation in the mutant mice, we conclude that SPNKA are not required for the normal processing of thermal information by these cells. However, the responses of NS neurons to noxious thermal stimulation are clearly critically dependent on the peptidergic input. Importantly, however, both NS and WDR lamina I neurons in mutant mice encoded thermal information. This is comparable with our previous report in these mice (Martin et al., 2004) where we observed a marked reduction of the responses of lamina $\mathrm{V}$ neurons to 45 and $49^{\circ} \mathrm{C}$ in mutant mice.

These data are also consistent with previous reports of behavioral deficits in animals lacking the PPT-A gene (Zimmer et al., 1998) and with our conclusion (Cao et al., 1998) that, although SP and NKA are important contributors to the behavioral response to noxious thermal stimuli, they are not required for intensity encoding. Presumably other neurotransmitters, likely glutamate and/or CGRP (calcitonin gene-related peptide), sufficiently activate dorsal horn neurons so as to maintain normal behavioral thresholds.

Despite our demonstration in that previous study of a behavioral deficit in the response to very intense, acute thermal stimulation, we did not find a deficit in the ability of the animal to manifest thermal allodynia/hyperalgesia after tissue injury [injection of complete Freund's adjuvant (CFA)]. Other laboratories, however, found impaired sensitization to thermal stimulation in NK1 receptor null mice, (Mansikka et al., 1999), which is consistent with our recent findings that neither WDR nor NS lamina I neurons in mutant mice showed thermal sensitization after MO injury. This contrasted with the neurons in the wt mice, which readily sensitized. The discrepancy of our present electrophysiological data with those of our previous behavioral studies could reflect the different agents used to produce tissue injury. CFA induces a delayed, immune-mediated inflammation that activates a broad range of primary afferents, whereas MO selectively activates TRPA1 receptors, which are present in a subpopulation 
A

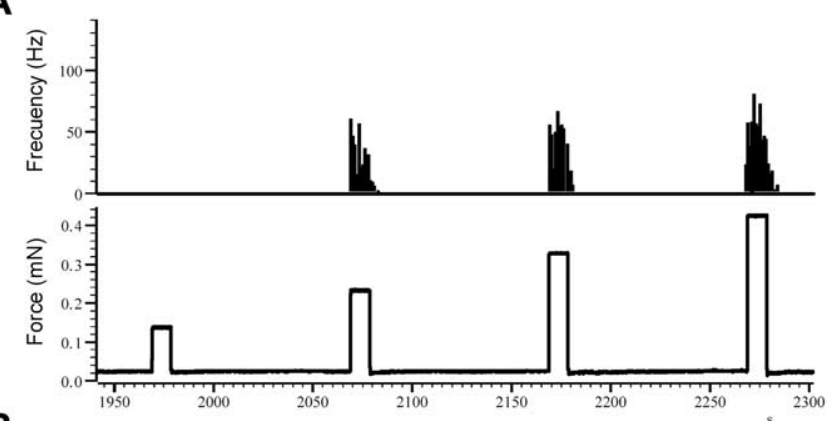

B

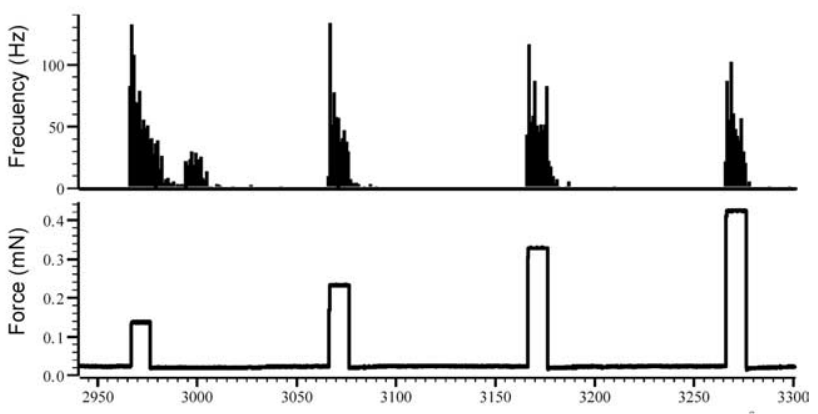

C

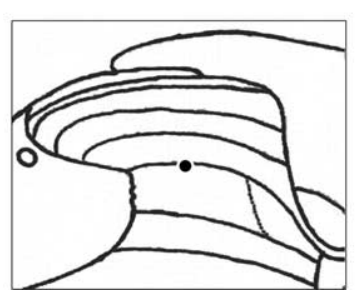

Figure 10. Example of the responses of a lamina $V$ neuron to graded mechanical stimuli before $(\boldsymbol{A})$ and $10 \mathrm{~min}$ after $(\boldsymbol{B})$ the application of mustard oil to the receptive field of the neuron. The recording site of the neuron is shown in $\boldsymbol{C}$.

of the TRPV1-expressing neurons, the majority of which in the mouse are peptidergic (Story et al., 2003; Bandell et al., 2004; Jordt et al., 2004; Kobayashi et al., 2005; Bautista et al., 2006). Conceivably, the very selective activation of peptidergic nociceptors revealed a contribution of tachykinins to injury-induced sensitization. Somewhat surprisingly, we did not observe sensitization at the higher stimulus temperatures $\left(45\right.$ and $\left.49^{\circ} \mathrm{C}\right)$. We suggest that the responses to these stimuli in the normal mouse are already near maximal.

Lamina I NS neurons in the mutant mice did not sensitize to thermal stimuli after MO, demonstrating that SP-NKA are significant contributors to the sensitization of this population of neurons to thermal stimuli. Surprisingly, lamina I WDR neurons also failed to sensitize after MO administration, although their responses to thermal stimulation seem to be independent of SPNKA. Conceivably, the critical component for sensitization of the lamina I WDR neurons in wt animals is input from silent nociceptors, which are very active after injury but not before. If the activity of silent nociceptors is SP-NKA dependent, their contribution to the firing of lamina I WDR neurons in the setting of tissue injury would be abrogated. These results contrast with our previous report in which we found that the deletion of SP-NKA in these animals did not prevent the ability of MO to sensitize lamina V neurons (Martin et al., 2004). The differential ability of neurons in lamina I and V to sensitize to thermal stimuli in the mutant mice highlights an important distinction between the
A
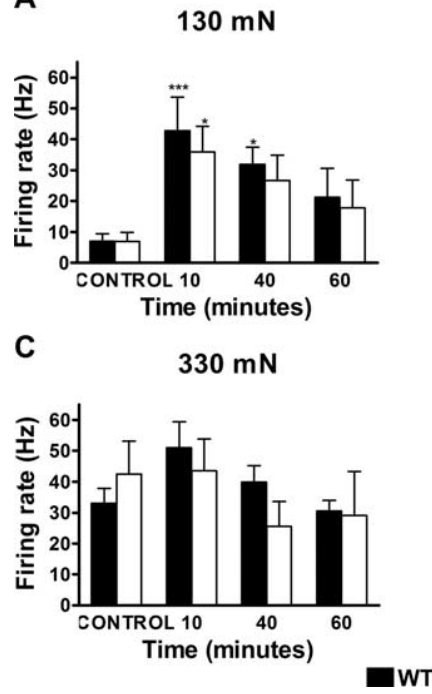

Figure 11. Lamina V: mustard oil sensitizes lamina V neurons to mechanical stimuli in both wt and mutant mice. Time course of the responses of lamina V neurons to $130 \mathrm{mN}(\boldsymbol{A}), 230 \mathrm{mN}$ (B), $330 \mathrm{mN}(\boldsymbol{C})$, and $430 \mathrm{mN}$ (D) mechanical stimuli before (CONTROL) and after the application of mustard oil, in wt (filled bars) and mutant (open bars) mice $\left({ }^{*} p<0.05,{ }^{* * *} p<0.001\right.$ vs control). Error bars indicate SEM.

contribution of tachykinins to the properties of these two major classes of nociresponsive dorsal horn neurons.

The apparently predominant effect of peptide inputs on lamina $\mathrm{V}$ neurons is surprising in light of our recent report that the nonpeptidergic nociceptors, via interneurons in lamina II, target lamina V, but not lamina I neurons (Braz et al., 2005). In contrast, lamina I neurons are clearly directly targeted by the peptidergic nociceptors (Liu et al., 1994). This, of course, does not rule out an indirect influence of the peptidergic nociceptors on these or other populations of lamina $\mathrm{V}$ nociresponsive neurons. In fact, SPsaporin ablation of lamina I neurons alters the properties of lamina $\mathrm{V}$ neurons, apparently via disruption of spinal-bulbo-spinal loops (Khasabov et al., 2005). Consistent with this hypothesis, we found that, although lamina $\mathrm{V}$ neurons in the mutant mice could be sensitized to thermal stimulation, the magnitude of the sensitization was somewhat reduced (Martin et al., 2004).

\section{Mechanical responsiveness of lamina I and $\mathrm{V}$ neurons}

Interestingly, the encoding of mechanical stimulus intensity by lamina I WDR and NS neurons did not differ between genotypes. We, therefore, conclude that neither SP nor NKA are required for the normal processing of mechanical stimuli by these neurons. The same is true for neurons in lamina $\mathrm{V}$, which showed no differences between wt and mutant mice. How these data relate to the behavioral deficits observed in the PPT-A mutant mice is unclear. Most importantly, the stimulus used in the behavioral analysis (tail clip) differs considerably from what we used in the present study. Tail clip is more intense and evokes a complex behavioral response (biting of the tail) that likely involves higher brain centers, in which loss of tachykinins may also be relevant. In contrast, it is unlikely that the properties of spinal cord neurons are influenced by loss of supraspinal tachykinins. Deficits in the processing of mechanical stimuli have also been observed in animals in which NK1-expressing cells were ablated from the superficial spinal cord (Mantyh et al., 1997; Khasabov et al., 2002). The difference between those data and our results presumably reflects the fact that SP-saporin treatment eliminates the NK1 receptor- 
expressing neurons in lamina I as well as those located deeper that extend their dendrites into laminae I and II. In the PPT-A mutant mice, these neurons are preserved and continue to receive normal glutamatergic input from peptidergic nociceptors.

\section{Lack of sensitization of lamina I neurons}

There is not complete agreement as to whether mustard oil can induce sensitization to mechanical stimulation (Reeh et al., 1986; Handwerker et al., 1987; Woolf et al., 1994; Schmelz et al., 1996; Mansikka and Pertovaara, 1997; Martin et al., 2001; García-Nicas et al., 2006). We found that MO did not sensitize lamina I neurons to mechanical stimulation, even in wt mice. This does not reflect a general failure of MO to sensitize lamina I neurons because MO significantly enhanced the responses of WDR and NS lamina I neurons to thermal stimulation and of lamina $\mathrm{V}$ neurons to mechanical stimulation. Again, this emphasizes the distinction between the properties of lamina I and V neurons.

Interestingly, high-threshold mechanoreceptive $\mathrm{C}$ nociceptors, which likely make monosynaptic connections with lamina I neurons, also do not sensitize to MO (Reeh et al., 1986; Handwerker et al., 1987; Schmelz et al., 1996). Lamina V neurons, however, integrate responses from a variety of peripheral sources, including direct $A \delta$ and $A \beta$ input, polysynaptic input from $C$ fibers as well as from spino-bulbospinal circuits. Any of these inputs could be the source of the mechanical sensitization that $\mathrm{MO}$ induces in lamina $\mathrm{V}$ neurons.

These results also do not imply that lamina I neurons are never sensitized to mechanical stimulation. Other chemical irritants, such as capsaicin, which excites a broader range of primary afferents, could trigger sensitization of the neurons to mechanical stimulation (Khasabov et al., 2002). It is of interest in this regard that, in the rat, García-Nicas et al. (2006) recently showed that some, but not all, NS lamina I neurons with A fiber input can sensitize to mechanical stimulation after capsaicin or MOinduced injury. The discrepancy between these data and our results could reflect a species difference. Specifically, this interesting population of NS with A-fiber input may be less abundant in mice.

In conclusion, our results demonstrate that SP and NKA are required for the processing of noxious thermal information under normal conditions and for the induction of thermal sensitization after MO injury but not for the processing of noxious mechanical information before or after MO injury. We also provide evidence that $\mathrm{MO}$ induces thermal and mechanical sensitization through neurochemically distinct mechanisms and that sensitization of lamina $\mathrm{V}$ neurons to a mechanical stimulus can occur without concurrent mechanical sensitization of neurons in lamina I.

\section{References}

Alexander M, Peters J, Mathie A, MacKenzie G, Smith A (2001) Nomenclature supplement. Trends Pharmacol Sci 94-95.

Bandell M, Story GM, Hwang SW, Viswanath V, Eid SR, Petrus MJ, Earley TJ, Patapoutian A (2004) Noxious cold ion channel TRPA1 is activated by pungent compounds and bradykinin. Neuron 41:849-857.

Bautista DM, Jordt SE, Nikai T, Tsuruda PR, Read AJ, Poblete J, Yamoah EN, Basbaum AI, Julius D (2006) TRPA1 mediates the inflammatory actions of environmental irritants and proalgesic agents. Cell 124:1269-1282.

Bessou P, Perl ER (1969) Response of cutaneous sensory units with unmyelinated fibers to noxious stimuli. J Neurophysiol 32:1025-1043.

Braz JM, Nassar MA, Wood JN, Basbaum AI (2005) Parallel "pain" pathways arise from subpopulations of primary afferent nociceptor. Neuron 47:787-793.

Cao YQ, Mantyh PW, Carlson EJ, Gillespie AM, Epstein CJ, Basbaum AI
(1998) Primary afferent tachykinins are required to experience moderate to intense pain. Nature 392:390-394.

Cuello AC, Kanazawa I (1978) The distribution of substance P immunoreactive fibers in the rat central nervous system. J Comp Neurol 178:129-156.

De Felipe C, Herrero JF, O'Brien JA, Palmer JA, Doyle CA, Smith AJ, Laird JM, Belmonte C, Cervero F, Hunt SP (1998) Altered nociception, analgesia and aggression in mice lacking the receptor for substance P. Nature 392:394-397.

García-Nicas E, Laird JM, Cervero F (2006) GABAA-receptor blockade reverses the injury-induced sensitization of nociceptor-specific (NS) neurons in the spinal dorsal horn of the rat. J Neurophysiol 96:661-760.

Handwerker HO, Anton F, Kocher L, Reeh PW (1987) Nociceptor functions in intact skin and in neurogenic or non-neurogenic inflammation. Acta Physiol Hung 69:333-342.

Hill R (2000) NK1 (substance P) receptor antagonists-why are they not analgesic in humans? Trends Pharmacol Sci 21:244-246.

Hökfelt T, Kellerth JO, Nilsson G, Pernow B (1975a) Substance P: localization in the central nervous system and in some primary sensory neurons. Science 190:889-890.

Hökfelt T, Kellerth JO, Nilsson G, Pernow B (1975b) Experimental immunohistochemical studies on the localization and distribution of substance $\mathrm{P}$ in cat primary sensory neurons. Brain Res 100:235-252.

Jordt SE, Bautista DM, Chuang HH, McKemy DD, Zygmunt PM, Hogestatt ED, Meng ID, Julius D (2004) Mustard oils and cannabinoids excite sensory nerve fibres through the TRP channel ANKTM1. Nature 427:260-265.

Khasabov SG, Rogers SD, Ghilardi JR, Peters CM, Mantyh PW, Simone DA (2002) Spinal neurons that possess the substance P receptor are required for the development of central sensitization. J Neurosci 22:9086-9098.

Khasabov SG, Ghilardi JR, Mantyh PW, Simone DA (2005) Spinal neurons that express NK-1 receptors modulate descending controls that project through the dorsolateral funiculus. J Neurophysiol 93:998-1006.

Kobayashi K, Fukuoka T, Obata K, Yamanaka H, Dai Y, Tokunaga A, Noguchi K (2005) Distinct expression of TRPM8, TRPA1, and TRPV1 mRNAs in rat primary afferent neurons with adelta/c-fibers and colocalization with trk receptors. J Comp Neurol 493:596-606.

Laird JM, Roza C, De Felipe C, Hunt SP, Cervero F (2001) Role of central and peripheral tachykinin NK1 receptors in capsaicin-induced pain and hyperalgesia in mice. Pain 90:97-103.

LaMotte CC (1988) Lamina X of primate spinal cord: distribution of five neuropeptides and serotonin. Neuroscience 25:639-658.

Liu H, Brown JL, Jasmin L, Maggio JE, Vigna SR, Mantyh PW, Basbaum AI (1994) Synaptic relationship between substance P and the substance P receptor: light and electron microscopic characterization of the mismatch between neuropeptides and their receptors. Proc Natl Acad Sci USA 91:1009-1013.

Mansikka H, Pertovaara A (1997) Supraspinal influence on hindlimb withdrawal thresholds and mustard oil-induced secondary allodynia in rats. Brain Res Bull 42:359-365.

Mansikka H, Shiotani M, Winchurch R, Raja SN (1999) Neurokinin-1 receptors are involved in behavioral responses to high-intensity heat stimuli and capsaicin-induced hyperalgesia in mice. Anesthesiology 90:1643-1649.

Mansikka H, Sheth RN, DeVries C, Lee H, Winchurch R, Raja SN (2000) Nerve injury-induced mechanical but not thermal hyperalgesia is attenuated in neurokinin-1 receptor knockout mice. Exp Neurol 162:343-349.

Mantyh PW, Rogers SD, Honore P, Allen BJ, Ghilardi JR, Li J, Daughters RS, Lappi DA, Wiley RG, Simone DA (1997) Inhibition of hyperalgesia by ablation of lamina I spinal neurons expressing the substance P receptor. Science 278:275-279.

Martin WJ, Malmberg AB, Basbaum AI (2001) PKC $\gamma$ contributes to a subset of the NMDA-dependent spinal circuits that underlie injury-induced persistent pain. J Neurosci 21:5321-5327.

Martin WJ, Cao Y, Basbaum AI (2004) Characterization of wide dynamic range neurons in the deep dorsal horn of the spinal cord in preprotachykinin-a null mice in vivo. J Neurophysiol 91:1945-1954.

Martinez-Caro L, Laird JM (2000) Allodynia and hyperalgesia evoked by sciatic mononeuropathy in NKI receptor knockout mice. NeuroReport 11:1213-1217.

Moochhala SM, Sawynok J (1984) Hyperalgesia produced by intrathecal substance $\mathrm{P}$ and related peptides: desensitization and cross desensitization. Br J Pharmacol 82:381-388. 
Reeh PW, Kocher L, Jung S (1986) Does neurogenic inflammation alter the sensitivity of unmyelinated nociceptors in the rat? Brain Res 384:42-50.

Schmelz M, Schmidt R, Ringkamp M, Forster C, Handwerker HO, Torebjork HE (1996) Limitation of sensitization to injured parts of receptive fields in human skin C-nociceptors. Exp Brain Res 109:141-147.

Story GM, Peier AM, Reeve AJ, Eid SR, Mosbacher J, Hricik TR, Earley TJ, Hergarden AC, Andersson DA, Hwang SW, McIntyre P, Jegla T, Bevan S, Patapoutian A (2003) ANKTM1, a TRP-like channel expressed in nociceptive neurons, is activated by cold temperatures. Cell 112:819-829.

Todd AJ, Puskar Z, Spike RC, Hughes C, Watt C, Forrest L (2002) Projection neurons in lamina $\mathrm{I}$ of rat spinal cord with the neurokinin 1 receptor are selectively innervated by substance P-containing afferents and respond to noxious stimulation. J Neurosci 22:4103-4113.
Weng HR, Mansikka H, Winchurch R, Raja SN, Dougherty PM (2001) Sensory processing in the deep spinal dorsal horn of neurokinin-1 receptor knockout mice. Anesthesiology 94:1105-1112.

Woolf CJ, Shortland P, Sivilotti LG (1994) Sensitization of high mechanothreshold superficial dorsal horn and flexor motor neurones following chemosensitive primary afferent activation. Pain 58:141-155.

Yaksh TL, Jessell TM, Gamse R, Mudge AW, Leeman SE (1980) Intrathecal morphine inhibits substance $\mathrm{P}$ release from mammalian spinal cord in vivo. Nature 286:155-157.

Yasphal K, Wright DM, Henry JL (1982) Substance P reduces tail-flick latency: implications for chronic pain syndromes. Pain 14:155-167.

Zimmer A, Zimmer AM, Baffi J, Usdin T, Reynolds K, Konig M, Palkovits M, Mezey E (1998) Hypoalgesia in mice with a targeted deletion of the tachykinin 1 gene. Proc Natl Acad Sci USA 95:2630-2635. 